\title{
Timing of planulation by pocilloporid corals in the northwestern Philippines
}

\author{
R. D. Villanueva, H. T. Yap*, M. N. E. Montaño \\ The Marine Science Institute, College of Science, University of the Philippines, Diliman, 1101 Quezon City, Philippines
}

\begin{abstract}
We determined the lunar, seasonal, and diel timing of larval release in several species in the scleractinian family Pocilloporidae at Bolinao in the northwestern Philippines. All of the species exhibited remarkable lunar periodicity in planula release, with distinct timing in the lunar calendar. Despite confinement of peak larval release between the first quarter and full moons in 4 species (Pocillopora damicornis, P. verrucosa, Stylophora pistillata, and Seriatopora guttatus), only the 2 Pocillopora species experienced significant overlap in release times. Disparate lunar timing, on the other hand, was exhibited by the 3 Seriatopora species (new moon for $S$. caliendrum, last quarter moon for $S$. hystrix, and full moon for $S$. guttatus) during warm-dry months, although during seasons with low planulation rates the timing for the former 2 species seemed to overlap. Generally, lunar reproductive patterns in each species were seasonally consistent despite strong variations in larval output. The highest rates of planulation were recorded during the warm-dry months (March to May) and the lowest during the warm-wet months (June to October), except for P. damicornis, in which the lowest rate occurred during the cool-dry months (November to February). The timing of release in $P$. damicornis is mainly during the dark period of the diel cycle, with a peak at ca. 02:30 h. This report highlights the variation in timing of planulation among closely related coral species and compares temporal planulation data in the Philippines, which lies within the Indo-West Pacific center of coral diversity, to available data on brooding pocilloporid corals from other biogeographic regions.
\end{abstract}

KEY WORDS: Pocillopora $\cdot$ Seriatopora $\cdot$ Stylophora $\cdot$ Reproduction $\cdot$ Planulae $\cdot$ Lunar periodicity Seasonality $\cdot$ Bolinao $\cdot$ Brooder

Resale or republication not permitted without written consent of the publisher

\section{INTRODUCTION}

The timing and synchrony in the reproduction of reef corals have profound consequences for coral population dynamics, notably recruitment patterns. Different coral species exhibit a range of different reproductive strategies even under similar ecological conditions (Fadlallah 1983, Richmond \& Hunter 1990). Prevailing ecological theory suggests that the evolution of such a diversity of reproductive and recruitment patterns has ensured the continued survival and maintenance of species under changing environments over time (Grahame \& Branch 1985). What remains unclear is the ecological significance of the existence of different planulation schedules even in closely related brooding coral species. One possibility is that this could help reduce competition for available space upon settlement, which is usually confined to relatively clear, hard (rocky or calcareous) surfaces (Fadlallah 1983). Space on the reef is continually being created due to mortality or dislodgement of benthic organisms. The release of planulae at different times would take advantage of this dynamic, temporal mosaic of space availability, thereby potentially enhancing the coexistence of a larger number of species on the reef.

In addition, if planula release by several species is not confined to a single window in time, it reduces the risk of catastrophic effects at the community level should a large-scale perturbation occur during this same period (Richmond \& Hunter 1990). From this perspective, planulation by several species distributed across different times again helps ensure the survival of more of these species. 
There is a growing body of observations of the temporal pattern of reproduction of reef corals, among the most remarkable of which is the synchronous, multispecific spawning of species in the Great Barrier Reef occurring a few nights after late spring full moon (Harrison et al. 1984). However, this account pertains to the release of gametes followed by external fertilization (rather than to the release of internally brooded larvae). The gamete release in these organisms is generally timed into some environmental cycles, which include diel, lunar, and seasonal ones (see Fadlallah 1983, Richmond \& Hunter 1990 for reviews). Cues from these cycles may promote synchronization of gamete release in broadcasting species, thereby potentially maximizing fertilization and allowing cross-fertilization (Harrison et al. 1984), as well as hybridization (Willis et al. 1997). Furthermore, synchronization of spawning can reduce predation of the propagules through predator satiation (Oliver et al. 1988).

In brooding species, these cycles appear to offer reliable cues for the timing of release for enhanced survival as well as dispersal and/or retention of the planktonic larvae (Morgan 1995). Aside from the environmental factors, however, it is possible that some internal (Giese 1959, Ims 1990) and social (Ims 1990) cues could also operate to effect temporal clustering of reproduction. Comparison of the temporal pattern of reproduction in closely related coral species within a similar ecological setting may lead to the identification of proximal and ultimate factors governing the timing of reproduction.

The lunar periodicity in larval release of brooding scleractinian corals has been an area of interest to coral biologists since the discovery of its occurrence in Pocillopora damicornis (= P. bulbosa) during the Great Barrier Reef Expedition of 1928-29 (Marshall \& Stephenson 1933). Although a number of brooding corals exhibit such a reproductive pattern, protracted larval release during a whole lunar cycle is evident in others (see reviews by Fadlallah 1983, Richmond \& Hunter 1990).

The environmental correlates that could help account for lunar periodicity in the breeding of corals and other marine invertebrates include nocturnal illumination (Levy et al. 2007), tide-driven current velocity, and water pressure (Korringa 1947). Indeed, night irradiance has been demonstrated to govern the lunar timing of planula release in 2 morphs of the coral Pocillopora damicornis in Hawaii (Jokiel et al. 1985). It has been suggested that nocturnal predation could be enhanced when moonlight is brightest, favoring release during new moon (Morgan 1995). Furthermore, the significance of the timing within the lunar cycle when coral larvae are released could lie in the maximization of larval dispersal or retention as influ- enced by the intensity of tidal currents. Corals that release larvae during spring tides (primarily during new and full moon phases) will likely experience longrange dispersal, while larval retention or localized dispersal will be expected for those releasing planulae during neap tides (first and third quarter moons) (Morgan 1995).

The seasonality in the release of sexual products may be determined by fluctuations in photoperiod, temperature, rainfall, and food availability (see Giese \& Kanatani 1987 for review). This seasonality has been shown to break down at lower latitudes due to environmental stability (Oliver et al. 1988), although more recent studies have found seasonality of reproduction even in equatorial assemblages of broadcasting corals (Baird et al. 2001, Penland et al. 2004, Guest et al. 2005). Seasonality has been demonstrated in brooding corals from reefs at varying latitudes (e.g. Harriott 1983, Kojis \& Quinn 1984, Tanner 1996, McGuire 1998).

In terms of diel cycles, most broadcasting reef corals release gametes a few hours after onset of darkness (Harrison et al. 1984, Fukami et al. 2003, Levitan et al. 2004, Penland et al. 2004). Known exceptions are the daytime gamete release in some broadcasting pocilloporids (Kinzie 1993) and agariciids (Marshall \& Stephenson 1933, Glynn et al. 1996, Plathong et al. 2006). In brooding corals, it has generally been accepted that planulation occurs at night, although evidence to demonstrate such timing is still insufficient. However, larvae can be released during the day in the presence of stress, e.g. handling and temperature. Release of reproductive products during darkness is presumed to be able to prevent predation by visual hunters (Johannes 1978, Babcock et al. 1986). The fitness of propagules released at this time is also enhanced through the absence of possible thermal stress and photodamage (Morgan 1995).

Here we report the lunar and seasonal timing of planula release in 6 species of the family Pocilloporidae (Pocillopora damicornis, P. verrucosa, Stylophora pistillata, Seriatopora caliendrum, S. hystrix, and $S$. guttatus) in Bolinao, northwestern Philippines. The diel timing of planulation was also determined for P. damicornis.

The pocilloporid corals possess various reproductive strategies, but are primarily simultaneous hermaphrodites, undergo internal fertilization, and exhibit internal brooding of planula larvae. Also, various reproductive schedules have been reported in pocilloporid populations from different biogeographic regions (see Fadlallah 1983, Richmond \& Hunter 1990 for reviews). In the Indo-West Pacific center of coral diversity, however, there still exist limited data on the timing of planulation of these organisms. 


\section{MATERIALS AND METHODS}

Mature colonies ( $>10 \mathrm{~cm}$ mean diameter) of 6 pocilloporid corals were collected from 2 sites in Bolinao, northwestern Philippines (see Table 1 for species and collection details). Morphological distinctions among species are based on Veron (2000). Colonies were collected $1 \mathrm{~d}$ prior to commencement of planulation monitoring. Upon collection, the colonies were transported a few kilometers from the reef to the hatchery facility of the Marine Science Institute's Bolinao Marine Laboratory for ex situ monitoring of planulation. Ex situ planulation monitoring has previously been shown to capture the same temporal pattern in planula release as that in the field (Jokiel et al. 1985, Zakai et al. 2006). Monitoring of planulation started at new moon $( \pm 1 \mathrm{~d})$. Lunar day (LD) 0 corresponds to the new moon.

To observe planula release, colonies were transferred separately to individual plastic translucent buckets (25 $\mathrm{cm}$ in diameter and $25 \mathrm{~cm}$ in depth) with a water outlet constructed near the brim. During the day, aeration and flow-through sand-filtered seawater was supplied. Seawater inflow was interrupted (while aeration was continued) from 17:00 $\mathrm{h}$ until 09:00 $\mathrm{h}$ the following morning (see data on diel timing of planula release in 'Results' for justification of this procedure). Before seawater inflow was resumed, the seawater (ca. $10 \mathrm{l}$ ) in which the coral was incubated during the evening was filtered using a nylon screen ( $215 \mu \mathrm{m}$ mesh) to collect any planula released. Planulae that settled on the bucket walls, aeration tube, and stone were counted and removed. Collected planulae were counted visually with the aid of a Pasteur pipette. Planula collection was conducted daily for 29 to $30 \mathrm{~d}$, thus covering 1 complete lunar cycle. No planula was recovered from a bucketful of hatchery seawater (sand-filtered) as monitored daily over a complete lunar cycle.

The monitoring scheme allowed the incubation buckets to be cleaned on a daily basis. Corals were fed with brine shrimp nauplii every 2 wk during the monitoring period. Colonies experiencing partial or total bleaching or mortality during the experiment were excluded from the data analysis.

After a month-long period of monitoring, the corals were returned to their source reef and retrieved during the next season (after at least 1 lunar cycle). Partial to total mortality, or bleaching, was experienced by some of the colonies in the reef, especially the Seriatopora spp., so that newly collected ones replaced them for the next monitoring run. For the colonies that appeared to be healthy, it was assumed that transport to the laboratory, then back to the source reef, and back again to the laboratory the following season did not significantly affect their reproductive output. Daily larval release was monitored for each species during 3 complete lunar cycles representing the 3 distinct seasons in the study site: warm-dry from March to May, warm-wet from June to October, and cool-dry from November to February.

To observe diel timing in planula release, colonies were monitored every $2 \mathrm{~h}$ (within a $24 \mathrm{~h}$ period), i.e. with renewal of incubation water during each interval. Aeration, but not flow-through seawater, was supplied throughout the monitoring period. This monitoring was conducted on colonies that were expected to release considerable numbers of larvae, i.e. around their peak planulation schedule. Observations on diel timing of planula release were conducted only for Pocillopora damicornis (23-24 June and 20-21 September 2004, LD 5-6, 6-7; $\mathrm{n}=4$ colonies each period).

To determine lunar periodicity in planulation for colonies releasing at least 5 larvae $(n \geq 5)$ in an entire lunar cycle, daily planula counts were subjected to the nonparametric Rayleigh test (this and the following statistical procedures are described in Zar 1984). Whenever the null hypothesis of uniformity of distribution throughout the lunar cycle was rejected, the mean lunar day (MD) of planula release for the colony was calculated using circular statistics.

At the species level, the null hypothesis that planula release is uniformly distributed throughout the lunar cycle was tested using the Moore modification of the Rayleigh test for circular uniformity. Data used in this test were the daily planula counts per colony, as normalized to the total planulae released by the colony for the entire lunar cycle. Only colonies that showed nonuniform distribution of release, as previously determined from the Rayleigh test, were included in this analysis. For species exhibiting lack of uniform lunar distribution, grand mean lunar day (GMD) and confidence limits of planula release were calculated using second-order statistical analysis for circular distributions. The circular statistic $r$ was also calculated as a measure of temporal concentration of planula release within the lunar calendar for each species, with $r$ ranging from 0 to 1 (where 0 indicates high dispersion and 1 indicates lack of dispersion, or planula release concentrated in $1 \mathrm{LD}$ ).

To test if 2 species exhibited significant overlap in lunar timing of larval release, a nonparametric 2sample second-order analysis of angles, with subsequent treatment with the Watson 2-sample test, was employed.

The Moore modification of the Rayleigh test was also conducted on the diel planulation data (colony planula count every $2 \mathrm{~h}$ normalized to the total planulae released by the colony for the entire diel cycle) collected for Pocillopora damicornis to determine diel periodicity in larval release. Mean hour and confidence intervals of planula release were also calculated. 


\section{RESULTS}

\section{Lunar periodicity}

All species released larvae with marked lunar periodicity (Table 1). Only data for the warm-dry season, when observed numbers of planulae were highest, are included in Table 1. As detailed later in this section, patterns for the other seasons were similar.

The different species exhibited variable degrees of temporal concentrations of release times, with the 3 Seriatopora species yielding the highest $r$ values, and Stylophora pistillata the lowest (Table 1). Most of the $S$. pistillata colonies monitored had only a few days within the cycle in which no larvae were extruded, thus having the most protracted release among the species investigated (Fig. 1). On the other hand, Seriatopora caliendrum colonies released larvae during a few days only and underwent a long quiescent period within the lunar month (Fig. 1).

It is noteworthy that between the first quarter and the full moon 4 species (Pocillopora damicornis, P. verrucosa, Stylophora pistillata, and Seriatopora guttatus) had their highest larval release rates with most colonies experiencing maximal releases (Fig. 1). The calculated GMDs of planula release for these species fall between these lunar phases (LD 10-14, Table 1), although Watson's 2-sample test revealed a significant overlap in planulation timing only between the 2 Pocillopora species (Table 1). Conversely, the 3 Seriatopora species exhibited variable, non-overlapping release times: around new moon for $S$. caliendrum, between last quarter and new moon for $S$. hystrix, and full moon for S. guttatus (Table 1, Fig. 1).

The lunar timing of planula release in each of the species was generally consistent during different seasons. The GMDs of planula release in $P$. damicornis were at LD 10, 9, and 9 (i.e. several days after first quarter moon) during the warm-dry, warm-wet, and cool-dry months, respectively. A similar temporal pattern was recorded for P. verrucosa (GMDs: LD 11, 10, and 7)

Only 4 out of 5 Stylophora pistillata colonies monitored showed significant lunar periodicity (Rayleigh test; $\mathrm{z}=1097.91,263.97,35.04$ and $4.29 ; \mathrm{p}<0.05$ ) during the cool-dry season, with an average MD at LD 11, which is within the confidence limits of GMD for the species during peak planulation in the warm-dry season (Table 1). During the warm-wet season, 5 of the 10 colonies monitored did not release any larvae, 1 colony released only 1 larva (not appropriate for statistical analysis), and 1 of the 4 colonies releasing $\geq 5$ larvae had uniform lunar distribution of planulation (Rayleigh test, $\mathrm{z}=1.64, \mathrm{p}>0.1)$. The 3 colonies that exhibited non-uniform distribution (Rayleigh test, $\mathrm{z}=5.18,4.36$

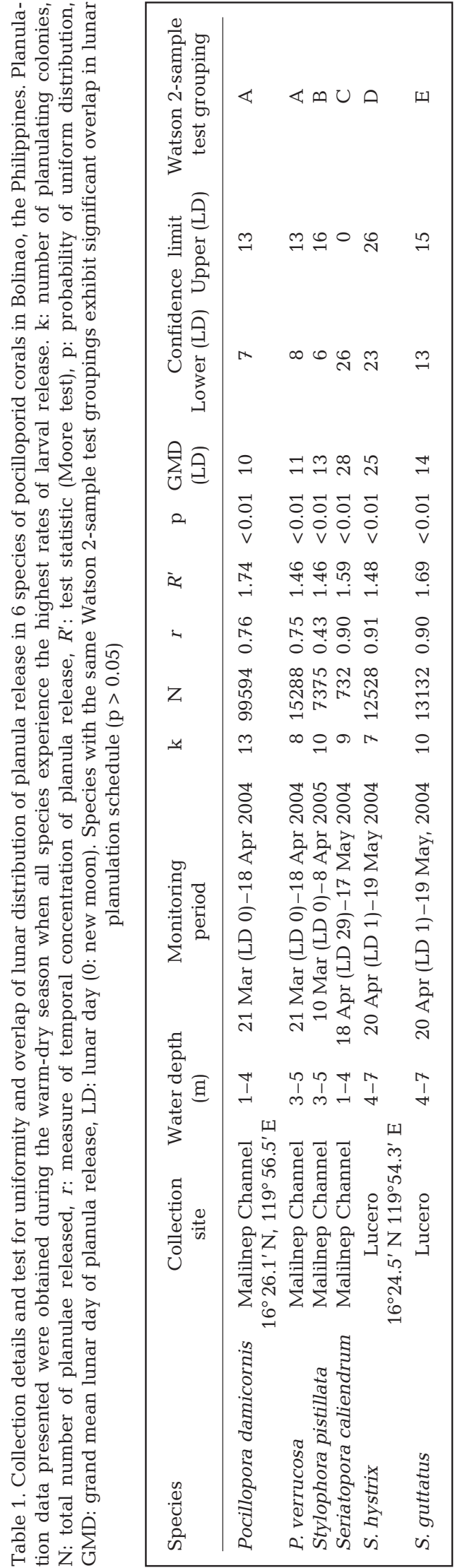


and 15.14; $\mathrm{p}<0.01$ ) had MDs at LD 10, 11, and 15, which are comparable to lunar release times during the other 2 seasons at the study site.

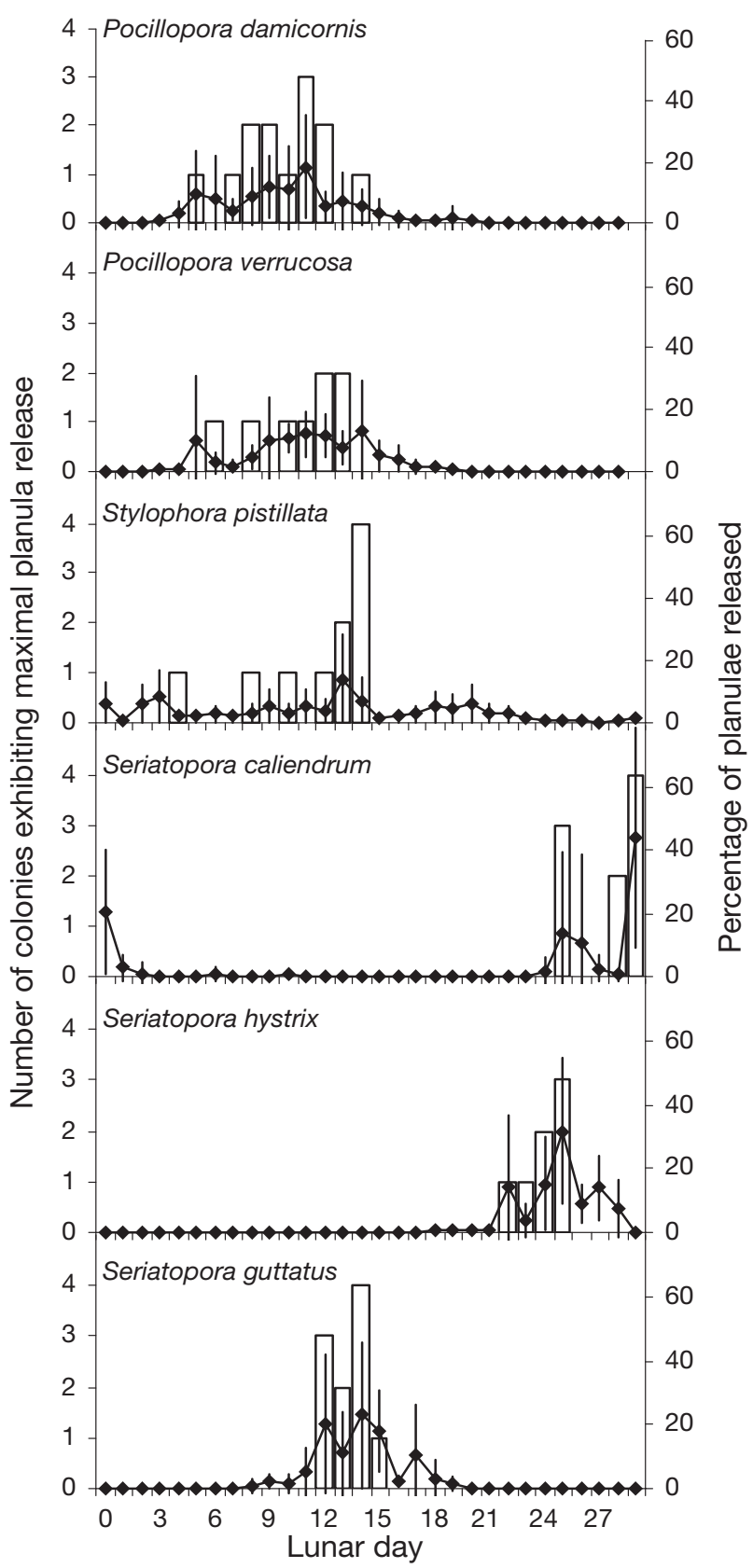

Fig. 1. Timing of planula release in 6 species of pocilloporid corals within the lunar calendar is shown as the frequency of colonies exhibiting maximal release (bar graphs), as calculated from circular statistics, and percentage of planulae released during the entire lunar cycle per colony (line graphs, mean $\pm \mathrm{SD}$ ). Planulation data were obtained during the warm-dry months when all species experienced the highest rates of larval release. See Table 1 for monitoring dates, number of colonies monitored for each species, and results of circular statistics performed. Lunar day $0=$ new moon
During the warm-wet season, 2 Seriatopora caliendrum colonies released larvae with significant periodicities (Rayleigh test, $\mathrm{z}=5.05$ and 6.77, $\mathrm{p} \leq 0.005$ ), with MDs at LD 0 and 1 (around new moon). During this time, 4 monitored colonies did not planulate, and 4 released $<5$ larvae. In the cool-dry season, only 1 of the 5 monitored colonies released $>5$ larvae, and planulation also occurred around new moon (MD: LD 27; Rayleigh test, $\mathrm{p}<0.001)$. Such release times are similar to the schedule during warm-dry months (Table 1), when all monitored colonies released relatively higher numbers of larvae.

The schedule of planulation for Seriatopora hystrix during the warm-wet season was close to the new moon (GMD: LD $27 \pm 2$, with 9 colonies monitored, all of which released $>5$ larvae), quite similar to the warm-dry months (Table 1). However, a slight shift in timing was detected during the cool-dry months, with GMD at new moon (LD $1 \pm 1$ ).

Consistent lunar timing was observed for Seriatopora guttatus, i.e. around the full moon, during all seasons. Despite the low percentage $(22 \%)$ of colonies releasing >5 larvae during the warm-wet months, these colonies displayed lunar periodicities (Rayleigh test, $\mathrm{z}=24.72$ and $37.83, \mathrm{p} \leq 0.005$ ) with MDs at LD 12 and 14 . All colonies released $>5$ larvae during the cooldry and warm-dry months, with lunar periodicities of release (Moore modification of Rayleigh test, $R^{\prime}=1.475$ and 1.693, p < 0.01) and GMDs at LD $17 \pm 2$ and $14 \pm 1$, respectively.

\section{Seasonality and diel timing}

All species planulated during the 3 distinct seasons, although their larval output varied from season to season, with the highest numbers recorded in all species during the warm-dry season (Fig. 2). For Pocillopora damicornis, relatively significant output also occurred during the warm-wet season, i.e. in contrast to the other species that released the lowest numbers of larvae during this period. Reproductive outputs increased during the cool-dry season, i.e. with reference to the preceding warm-wet season, except $P$. damicornis.

Pocillopora damicornis released larvae with marked diel periodicity (Fig. 3, Moore modification of Rayleigh test, $\left.R^{\prime}=1.497, \mathrm{p}<0.005\right)$. The mean time for planula release was around 02:30 h (confidence limits: 01:00 to 04:00 h). Despite major planulation during the night, a low percentage of larvae was still released during daytime, with $6 \pm 3 \%$ of the total larval output throughout the entire diel cycle released between 09:00 and 17:00 $\mathrm{h}$ (the period when flow-through seawater was restored). 

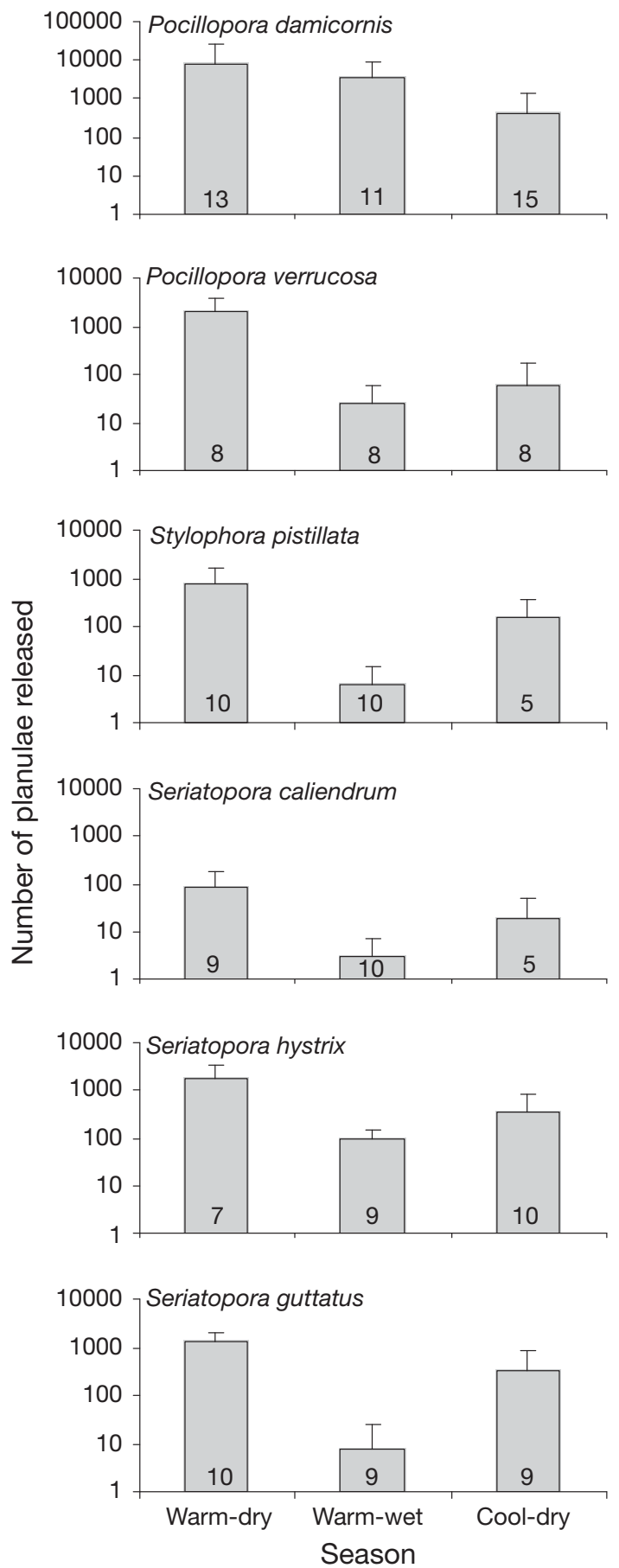

Fig. 2. Seasonality of planula release in 6 species of pocilloporid corals. Data presented as number of planulae released during an entire lunar cycle per colony (mean \pm SD). Planulation monitoring schedule: warm-dry: see Table 1 for all species; warm-wet: June-July 2004 ( $P$. damicornis and $P$. verrucosa), July-August 2004 (S. hystrix and S. guttatus), August-September 2004 (S. pistillata), September-October 2004 (S. caliendrum); cool-dry: November-December 2003 ( $P$. damicornis and $P$. verrucosa), November-December 2004 (S. pistillata and S. caliendrum), January-February 2005 (S. hystrix and $S$. guttatus). Number at the base of each bar indicates the number of colonies monitored

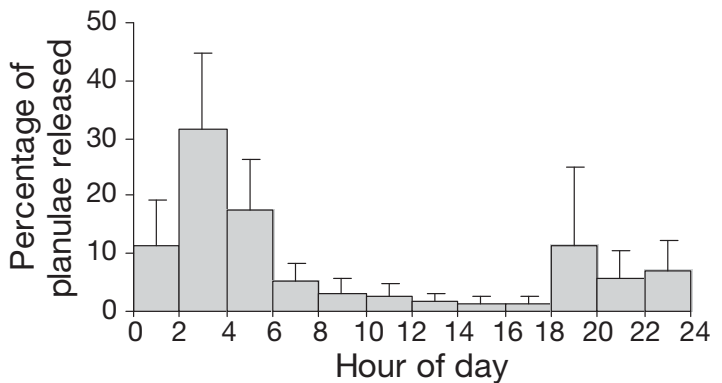

Fig. 3. Pocillopora damicornis. Diel timing of planula release. Larvae released during the $2 \mathrm{~h}$ monitoring intervals are presented as percentage of the total larvae released within the diel cycle $(24 \mathrm{~h})$ per colony (mean $\pm \mathrm{SD})$

\section{DISCUSSION}

The present study determined the timing of larval release in closely related coral species of the family Pocilloporidae. For all 6 species investigated, remarkable lunar periodicity and distinct timing in planula release were observed. In addition, these reproductive patterns were seasonally consistent despite clear variations in larval output. The 2 Pocillopora species studied exhibited significant overlap in their lunar larval release times, with confinement of peak larval release between the first quarter and full moon, together with 2 other species (Stylophora pistillata and Seriatopora guttatus). Disparate lunar timing, on the other hand, was exhibited by the 3 Seriatopora species (S. caliendrum, S. hystrix and S. guttatus) during summer, although during seasons with low planulation rates the timing for the former 2 species seemed to overlap.

In some species, there appeared to be a high level of intercolony variability in the timing of peak larval release. This was attributed to varying degrees in the state of health of these colonies, rather than to intraspecific polymorphism.

A comparative study on the reproductive behavior of closely related species of Madracis in the Caribbean also showed interspecific differences, though small, in timing of larval release (Vermeij et al. 2003). In fact, subtle differences in planulation schedule have been used as a criterion in drawing a boundary between 2 Agaricia species (van Moorsel 1983).

We determined the lunar timing of planula release in at least 2 closely related species at each of our 2 study sites (refer to Table 1). At both sites, different lunar timing of release was observed between the species (Seriatopora hystrix and $S$. guttatus in Lucero; $S$. caliendrum and Pocillopora damicornis in Malilnep Channel). Since these species pairs have the same depth distributions, their asynchronous releases may reflect the lack of a local environmental factor that 
might serve as a proximal cue for planulation for both species at each site. The possible action of environmental cues on other phases of the reproductive cycle such as gametogenesis, male gamete spawning, and embryogenesis was not examined in the present study.

The lunar timing of larval release in Pocillopora damicornis is around the first quarter moon in Bolinao, northwestern Philippines. This widely distributed brooding coral also displays peak planulation during this moon phase in nearby southern Taiwan (Fan et al. 2002) and in Enewetak (Stimson 1978, Richmond \& Jokiel 1984). For other localities, peak larval release is at around new moon in Palau (Atoda 1947a), midway between full moon and third quarter moon in southwestern Japan (Tioho et al. 2001), third quarter moon in the southern Great Barrier Reef (Tanner 1996), and between full moon and new moon in Hawaii (Harrigan 1972). Furthermore, disparate planulation schedules within a lunar cycle were observed for morphospecies of $P$. damicornis in Hawaii, during first quarter moon for ' $\mathrm{B}$ ' morphs and third quarter moon for ' $\mathrm{Y}$ 's (Richmond \& Jokiel 1984). Such a pattern was shown to be determined by night irradiance (Jokiel et al. 1985). In addition, different lunar timing was observed in a $P$. damicornis population within a year, i.e. new moons during austral summer and full moons during winter (Marshall \& Stephenson 1933, Harriott 1983). This seesaw in reproductive timing has been attributed to the annual fluctuation in the occurrence of spring tide in the lunar calendar (Korringa 1947). Indeed, the causative environmental agent of the lunar timing in planula release in this well-studied coral species, as well as in other corals and marine organisms, remains elusive. The variable timing in planula release in various populations across biogeographic regions would also negate the operation of a universal environmental cue (colloquially known as a 'zeitgeber') as a proximate factor in the reproductive synchronization of corals. Temporal reproductive differences among allopatric populations have been suggested to represent adaptations to local environmental conditions and cues (Richmond \& Hunter 1990).

Lunar periodicity in planulation was also demonstrated by Seriatopora hystrix in various sites across the Pacific basin, though with variations in lunar timing: around new and first quarter moon in Palau (Atoda 1951) and Enewetak (Stimson 1978), first quarter moon in southern Taiwan (Fan et al.2002), third quarter moon in the Great Barrier Reef (Tanner 1996, as deduced from the occurrence of larvae in coral fragments), and between third quarter and new moon in the Philippines (the present study). Like in Pocillopora damicornis, different populations in different biogeographic regions do not planulate synchronously, lending support to the earlier hypothesis of the unlikely action of a moon-derived zeitgeber in the organization of planula release among brooding corals.

Lack of lunar periodicity in planula release has been observed in Stylophora pistillata in the Red Sea (Rinkevich \& Loya 1979, Shlesinger \& Loya 1985, but see Zakai et al. 2006) and is indicated by the relative uniformity in lunar distribution of larval occurrence in coral fragments in the Great Barrier Reef (Tanner 1996). However, such reproductive behavior is not the case for populations in the north Pacific (Palau, Atoda 1947b; Taiwan, Fan et al. 2002; Philippines, the present study). Weak but significant periodicity was detected in populations at the latter 2 locations.

Coral species that demonstrate diel periodicity in planulation release most of their larvae during the dark phase of the diel cycle (Fan et al. 2006, the present study). For Pocillopora damicornis, the dawn planulation in the northwestern Philippines corroborates the pattern observed in southern Japan (Isomura \& Nishihira 2001, Tioho et al. 2001) and southern Taiwan (Fan et al. 2006). The advantage of this particular timing in the dark period (i.e. close to sunrise) could be the prompt use of light cues for settlement by mature, competent larvae right after release, thus shortening the time spent in the plankton and promoting recruitment in the natal reef (Fan et al. 2006). Aside from the major planulation episode at dawn, a minor peak after dusk was detected, similar to the observation of Fan et al. (2006) for the same species and for the caryophylliid Euphyllia glabrescens. The explanation for this pattern remains unclear.

The seasonality of larval production in brooding corals has a consistent pattern across regions, with higher output or reproduction occurring only during warmer months (Stimson 1978, Johnson 1992, Tanner 1996, McGuire 1998, Vermeij et al. 2003), similar to the results of the present study. Temperature control in reproduction of corals has been suggested to influence their abundance (Jokiel \& Guinther 1978) and determine their geographic distribution (Yonge 1940). However, the possible effects of temperature on larval release and on subsequent recruitment and distribution of the different species in the reef were not included in this investigation.

\section{CONCLUSIONS}

The present study provides new information on the temporal patterns of planulation of 6 pocilloporid species in the northwestern Philippines, which is part of the Indo-West Pacific center of diversity for scleractinian corals. Distinct lunar periodicity was observed in all species, with little temporal overlap, suggesting that timing of larval release is species specific. In addition, 
even closely related species at the same depth in the same site or under the same ecological setting had different planulation schedules, reflecting possible evolutionary divergence (the reasons for which are not the subject of this investigation).

There is no common local environmental factor that acts as a proximal cue for larval release within the lunar cycle in this set of ecologically similar species. However, should there be a common moon-phasederived environmental cue affecting the reproduction of these species, it could have regulated the onset of gametogenesis and/or the spawning of male gametes. Periodicity in larval release is believed to be the result of earlier periodicity in spawning of male gametes (Tanner 1996). This possibility is worth investigating. It is also related to the broader question of whether selection has acted to influence the timing of sperm release (Levitan 1998). This would have implications for the success of fertilization or the prevention of hybridization. This process of selection could have acted differently on the different pocilloporid species in the course of their evolution.

In addition, development times could be different in the different species, possibly explaining differences in their larval release times even if the onset of embryogenesis might be synchronous. This represents a contrast to related species of Madracis in the Caribbean, for example, where the timing and patterns of reproductive development are similar (Vermeij et al. 2004). These are avenues for future research.

The general pattern observed for all species was the higher rate of planulation during the warm-dry months compared to other seasons. However, this pattern may be at risk of disruption with the projected warming of the oceans, indicated by recent global thermal trends (e.g. Hansen et al. 2006), as seasonal physico-chemical variables affecting coral biology, including reproduction, are altered (Olive 1995).

Acknowledgements. We thank M. Ponce for field and hatchery assistance. This study formed part of R.D.V.'s PhD dissertation. Funding was provided by Shell Philippines Exploration B.V. This is contribution no. 374 of the Marine Science Institute (University of the Philippines).

\section{LITERATURE CITED}

Atoda K (1947a) The larva and postlarval development of some reef-building corals. I. Pocillopora damicornis cespitosa (Dana). Sci Rep Tohoku Univ Fourth Ser (Biol) 18:24-47

Atoda K (1947b) The larva and postlarval development of some reef-building corals. II. Stylophora pistillata (Esper). Sci Rep Tohoku Univ Fourth Ser (Biol) 18:48-65

Atoda K (1951) The larva and postlarval development of some reef-building corals. V. Seriatopora hystrix Dana. Sci Rep Tohoku Univ Fourth Ser (Biol) 19:33-39

Babcock RC, Bull GD, Harrison PL, Heyward AJ, Oliver JK,
Wallace CC, Willis BL (1986) Synchronous spawning of 105 scleractinian coral species on the Great Barrier Reef. Mar Biol 90:379-394

Baird AH, Sadler C, Pitt M (2001) Synchronous spawning of Acropora in the Solomon Islands. Coral Reefs 19:286

Fadlallah YH (1983) Sexual reproduction, development and larval biology in scleractinian corals. Coral Reefs 2: $129-150$

Fan TY, Li JJ, Ei SX, Fang LS (2002) Lunar periodicity of larval release by pocilloporid corals in southern Taiwan. Zool Stud 41:288-294

Fan TY, Lin KH, Kuo FW, Soong K, Liu LL, Fang LS (2006) Diel patterns of larval release by five brooding scleractinian corals. Mar Ecol Prog Ser 321:133-142

Fukami H, Omori M, Shimoike K, Hayashibara T, Hatta M (2003) Ecological and genetic aspects of reproductive isolation by different spawning times in Acropora corals. Mar Biol 142:679-684

Giese AC (1959) Comparative physiology: annual reproductive cycles of marine invertebrates. Annu Rev Physiol 21: 547-576

Giese AC, Kanatani H (1987) Maturation and spawning. In: Giese AJ, Pearse JS, Pearse VB (eds) Reproduction of marine invertebrates, Vol 9. Academic Press, New York, p 251-329

Glynn PW, Colley SB, Gassman NJ, Black K, Cortes J, Mate JL (1996) Reef coral reproduction in the eastern Pacific: Costa Rica, Panama, and Galapagos Islands (Ecuador). 3. Agariciidae (Pavona gigantean and Gardineroseris planulata). Mar Biol 125:579-601

Grahame J, Branch GM (1985) Reproductive patterns of marine invertebrates. Oceanogr Mar Biol Annu Rev 23: 373-398

Guest JR, Baird AH, Goh BPL, Chou LM (2005) Reproductive seasonality in an equatorial assemblage of scleractinian corals. Coral Reefs 24:112-116

Hansen J, Sato M, Ruedy R, Lo K, Lea DW, Medina-Elizalde M (2006) Global temperature change. Proc Natl Acad Sci USA 103:14288-14293

Harrigan JF (1972) The planula larva of Pocillopora damicornis: lunar periodicity of swarming and substratum selection behavior. $\mathrm{PhD}$ dissertation. University of Hawaii at Manoa, Honolulu, HI

Harriott VJ (1983) Reproductive seasonality, settlement, and post-settlement mortality of Pocillopora damicornis (Linnaeus), at Lizard Island, Great Barrier Reef. Coral Reefs 2:151-157

> Harrison PL, Babcock RC, Bull GD, Oliver JK, Wallace CC, Willis BL (1984) Mass spawning in tropical reef corals. Science 223:1186-1189

Ims RA (1990) The ecology and evolution of reproductive synchrony. Trends Ecol Evol 5:135-139

Isomura N, Nishihira M (2001) Size variation of planulae and its effect on the lifetime of planulae in three pocilloporid corals. Coral Reefs 20:309-315

- Johannes RE (1978) Reproductive strategies of coastal marine fishes in the tropics. Environ Biol Fishes 3:65-84

Johnson KG (1992) Synchronous planulation of Manicina areolata (Scleractinia) with lunar periodicity. Mar Ecol Prog Ser 87:265-273

Jokiel PL, Guinther EB (1978) Effects of temperature on reproduction in the hermatypic coral Pocillopora damicornis. Bull Mar Sci 28:786-789

> Jokiel PL, Ito RY, Liu PM (1985) Night irradiance and synchronization of lunar release of planula larvae in the reef coral Pocillopora damicornis. Mar Biol 88:167-174

Kinzie RAI (1993) Spawning in the reef corals Pocillopora ver- 
rucosa and P. eydouxi at Sesoko Island, Okinawa. Galaxea 11:93-105

Kojis BL, Quinn NJ (1984) Seasonal and depth variation in fecundity of Acropora palifera at two reefs in Papua New Guinea. Coral Reefs 3:165-172

Korringa P (1947) Relations between the moon and periodicity in the breeding of marine animals. Ecol Monogr 17: $347-380$

Levitan DR (1998) Sperm limitation, gamete competition, and sexual selection in external fertilizers. In: Birkhead $\mathrm{T}$, Møller A (eds) Sperm competition and sexual selection. Academic Press, New York, p 173-215

Levitan DR, Fukami H, Jara J, Kline D and others (2004) Mechanisms of reproductive isolation among sympatric broadcast-spawning corals of the Montastraea annularis species complex. Evolution 58:308-323

Levy O, Appelbaum L, Leggat W, Gothlif Y, Hayward DC, Miller DJ, Hoegh-Guldberg O (2007) Light-responsive cryptochromes from a simple multicellular animal, the coral Acropora millepora. Science 318:467-470

Marshall SM, Stephenson TA (1933) The breeding of reef animals. Part I. The corals. Sci Rep Great Barrier Reef Exp 1928-29 3:219-247

McGuire MP (1998) Timing of larval release by Porites astreoides in the northern Florida Keys. Coral Reefs 17: 369-375

Morgan SG (1995) The timing of larval release. In: McEdward L (ed) Ecology of marine invertebrate larvae. CRC Press, Boca Raton, FL, p 157-191

> Olive PJW (1995) Annual breeding cycles in marine invertebrates and environmental temperature: probing the proximate and ultimate causes of reproductive synchrony. J Therm Biol 20:79-90

Oliver JK, Babcock RC, Harrison PL, Willis BL (1988) Geographic extent of mass coral spawning: cues to ultimate causal factors. Proc 6th Int Coral Reef Symp 2:803-811

Penland L, Kloulechad J, Idip D, van Woesik R (2004) Coral spawning in the western Pacific Ocean is related to solar insolation: evidence of multiple spawning events in Palau. Coral Reefs 23:133-140

Plathong S, Chanmethakul T, Suwonno V, Buaphet P, Baird $\mathrm{AH}$, Chen CA, Soontornpitakkool S (2006) Daytime gamete release from the reef-building coral, Pavona sp., in the Gulf of Thailand. Coral Reefs 25:72

Richmond RH, Hunter CL (1990) Reproduction and recruit-

Editorial responsibility: Don Levitan,

Tallahassee, Florida, USA ment of corals: comparisons among the Caribbean, the Tropical Pacific and the Red Sea. Mar Ecol Prog Ser 60:185-203

Richmond RH, Jokiel PL (1984) Lunar periodicity in larva release in the reef coral Pocillopora damicornis at Enewetak and Hawaii. Bull Mar Sci 34:280-287

Rinkevich B, Loya Y (1979) The reproduction of the Red Sea coral Stylophora pistillata. II. Synchronization in breeding and seasonality of planulae shedding. Mar Ecol Prog Ser $1: 145-152$

Shlesinger Y, Loya Y (1985) Coral community reproductive patterns: Red Sea versus the Great Barrier Reef. Science 228:1333-1335

> Stimson JS (1978) Mode and timing of reproduction in some common hermatypic corals of Hawaii and Enewetak. Mar Biol 48:173-184

Tanner JE (1996) Seasonality and lunar periodicity in the reproduction of pocilloporid corals. Coral Reefs 15:59-66

Tioho H, Tokeshi M, Nojima S (2001) Experimental analysis of recruitment in a scleractinian coral at high latitude. Mar Ecol Prog Ser 213:79-86

van Moorsel GWNM (1983) Reproductive strategies in two closely related stony corals (Agaricia, Scleractinia). Mar Ecol Prog Ser 13:273-283

> Vermeij MJA, Sampayo E, Bröker K, Bak RPM (2003) Variation in planulae release of closely related coral species. Mar Ecol Prog Ser 247:75-84

Vermeij MJA, Sampayo E, Bröker K, Bak RPM (2004) The reproductive biology of closely related coral species: gametogenesis in Madracis from the southern Caribbean. Coral Reefs 23:206-214

Veron JEN (2000) Corals of the world. Australian Institute of Marine Science, Townsville

Willis BL, Babcock RC, Harrison PL, Wallace CC (1997) Experimental hybridization and breeding incompatibilities within the mating systems of mass spawning reef corals. Coral Reefs 16:S53-S65

Yonge CM (1940) The biology of reef-building corals. Sci Rep Great Barrier Reef Exped 1928-29 1:353-403

> Zakai D, Dubinsky Z, Avishai A, Caaras T, Chadwick NE (2006) Lunar periodicity of planula release in the reefbuilding coral Stylophora pistillata. Mar Ecol Prog Ser 311:93-102

Zar JH (1984) Biostatistical analysis. Prentice-Hall, Englewood Cliffs, NJ

Submitted: July 6, 2005; Accepted: July 12, 2008

Proofs received from author(s): September 22, 2008 